\title{
Pipeline Pharmacological Therapies in Clinical Trial for COVID-19 Pandemic: a Recent Update
}

\author{
Puja Kumari ${ }^{1} \cdot$ Kajal Rawat ${ }^{1} \cdot$ Lekha Saha $^{1}$ (1) \\ Published online: 18 July 2020 \\ (C) Springer Nature Switzerland AG 2020
}

\begin{abstract}
The emergence of the severe acute respiratory syndrome coronavirus-2 (SARS-CoV-2), responsible for causing coronavirus disease 2019 (COVID-19), marked the third time in the twenty-first century when a new, highly pathogenic human coronavirus outbreak has led to an epidemic. The COVID-19 epidemic has emerged in late December 2019 in Wuhan city of China and spread rapidly to other parts of the world. This quick spread of SARS-CoV-2 infection to many states across the globe affecting many people has led WHO to declare it a pandemic on March 12, 2020. As of July 4, 2020, more than 523,011 people lost their lives worldwide because of this deadly SARS-CoV-2. The current situation becomes more frightening as no FDA-approved drugs or vaccines are available to treat or prevent SARS-CoV-2 infection. The current therapeutic options for COVID-19 are limited only to supportive measures and non-specific interventions. So, the need of the hour is to search for SARS-CoV-2-specific antiviral treatments and to develop vaccines for SARS-CoV2. Also, it is equally important to maintain our immunity, and natural products and Ayurvedic medicines are indispensable in this regard. In this review, we discuss recent updates regarding various therapeutic approaches to combat COVID-19 pandemic and enlist the major pipeline drugs and traditional medicines that are under trial for COVID-19. Also, possible mechanisms involved in viral pathogenesis are discussed, which further allow us to understand various drug targets and helps in discovering novel therapeutic approaches for COVID-19. Altogether, the information provided in this review will work as an intellectual groundwork and provides an insight into the ongoing development of various therapeutic agents.
\end{abstract}

Keywords COVID-19 $\cdot$ SARS-CoV-2 $\cdot$ Pipeline drugs $\cdot$ Pharmacological therapy $\cdot$ A recent update

\begin{tabular}{|c|c|c|c|}
\hline \multicolumn{3}{|c|}{ Abbreviations } & ACE2 \\
\hline \multicolumn{2}{|c|}{ COVID-19 } & Coronavirus disease 2019 & TMPRSS2 \\
\hline \multirow{2}{*}{\multicolumn{2}{|c|}{ SARS-CoV-2 }} & Severe acute respiratory syndrome & $\operatorname{RdRp}$ \\
\hline & & coronavirus 2 & 3CLPro \\
\hline \multirow{2}{*}{\multicolumn{2}{|c|}{ SARS-CoV }} & Severe acute respiratory & PD1 \\
\hline & & syndrome coronavirus & IL-6 \\
\hline \multirow{2}{*}{\multicolumn{2}{|c|}{ MERS-CoV }} & Middle East respiratory & NK cell \\
\hline & & syndrome coronavirus & $\mathrm{ARB}$ \\
\hline \multicolumn{2}{|c|}{ WHO } & World health organization & NSAID \\
\hline \multirow{2}{*}{\multicolumn{2}{|c|}{ ARDS }} & Acute respiratory distress syndrome & rbACE2 \\
\hline & & & BCG \\
\hline \multicolumn{3}{|c|}{ This article is part of the Topical Collection on Covid-19 } & \\
\hline & \multirow{3}{*}{\multicolumn{2}{|c|}{$\begin{array}{l}\text { Lekha Saha } \\
\text { saha.lekha@pgimer.edu.in; lekhasaha@ rediffmail.com }\end{array}$}} & $\mathrm{CQ}$ \\
\hline & & & $\mathrm{HCQ}$ \\
\hline & & & MSC \\
\hline 1 & Department & f Pharmacology, Post Graduate Institute of Medical & TCM \\
\hline
\end{tabular}

Angiotensin-converting enzyme 2

Transmembrane protease serine type 2

RNA-dependent RNA polymerase

3-chymotrypsin-like protease

Programmed cell death protein

Interleukin-6

Natural killer cell

Angiotensin receptor blocker

Nonsteroidal anti-inflammatory drug

Recombinant bacterial ACE2 receptors

Bacillus Calmette Guérin

Randomized control trial

Emergency use authorization

Chloroquine

Hydroxychloroquine

Mesenchymal stem cell

Traditional Chinese Medicine 


\section{Introduction}

The current Coronavirus Disease 2019 (COVID-19) has become a great threat to public health and has attracted the attention of the majority of scientists and researchers to develop a specific drug or vaccine to outweigh the threat to this pandemic. It was initially originated in Wuhan, Hubei Province of China, in December 2019, as pneumonia-like symptoms [1] and spread rapidly to other parts of the world, affecting 10,922,324 individuals, causing more than 523,011 fatalities in over 210 countries by July 4, 2020 [2]. It was discovered to cause by a novel coronavirus having more than $79 \%$ sequence homology with the severe acute respiratory syndrome coronavirus (SARS-CoV) and 96\% genome similarity with bat coronavirus [3], named as severe acute respiratory syndrome coronavirus 2 (SARS-CoV-2) by the International Committee on Taxonomy of Viruses [4]. Owing to the alarming level of its severity and rapid spread to many countries in a short period, the World health organization (WHO) has declared this epidemic as pandemic on March 12, 2020 [5]. COVID-19 pandemic is a pandemic of respiratory illness characterized by flu-like symptoms, sometimes associated with immune dysfunction and acute respiratory distress syndrome (ARDS), which might lead to death [6]. It is the third time in the twenty-first century, after severe acute respiratory syndrome (SARS) in 2002 and 2003 and Middle East respiratory syndrome (MERS) in 2012 when a highly pathogenic coronavirus of zoonotic origin has affected humans [7, 8]. To date, this has affected the lives of many people worldwide and put pressure on the health system and the global economy. SARS-CoV-2 has a high potential to cause infection with a higher transmission rate in comparison to SARS-CoV or MERS-CoV, making it difficult to control and thereby increasing its pandemic potential.

The current strategies followed by the government to reduce the spread of COVID-19 are based on the paradigm of social distancing, which includes identification of cases, tracing the contacts, and restrict them to quarantine and isolation. The current pharmacological therapy given is only restricted to supportive care and interventions that mitigate the associated symptoms. Many studies are being conducted nowadays in search of effective drugs for COVID-19 and also to develop efficient vaccines as a preventive therapy against COVID-19, yet to date, no licensed vaccines or effective antiviral drugs exist against SARS-CoV-2 infections. So, many individuals may turn to validated Ayurvedic and herbal medicines to boost the immune system. However, considering such therapies requires consideration of the potential benefits and harms. The need of the hour is to develop specific antiviral drugs for COVID-19, which would stop the viral replication at the beginning and might reduce the associated degree of immunopathological damage. Also, the role of immunologically directed strategies and anti-cytokine therapy is indispensable in
SARS-CoV-2 infection as a notable proportion of COVID-19 patients have reported an impaired immune system and cytokine storm, which might damage the lungs and also lead to acute respiratory distress syndrome (ARDS). In this regard, many drugs previously used to treat SARS and MERS and other viral diseases, including Ebola, HIV, and Influenza, have been evaluated and demonstrated effect in various in vitro studies or patients of COVID-19. Also, traditionally used medicinal compounds such as purified natural and herbal medicines, and Ayurvedic and traditional Chinese medicines are being evaluated and many of them have evidence supporting efficacy against COVID-19. Nonetheless, additional data are urgently needed. Herein we discuss the novel strategies and targets that could be approached for the development of drugs against COVID-19. This review highlights the majority of pipeline drugs that are currently being studied in clinical trials for COVID-19 and discuss the present and future aspects of most promising drugs under investigation.

\section{SARS-CoV-2: Virology and Targets for Drug Development}

SARS-CoV-2 is an enveloped non-segmented positive sense single-strand RNA viruses classified into the genus Betacoronavirus in the subfamily Orthocoronavirinae [9]. After SARS-CoV and MERS-CoV, it has become the seventh coronavirus that causes infection in human beings. The receptor-binding domain present in the $\mathrm{S} 1$ subunit of the spike protein $(\mathrm{S})$ is responsible for targeting the host cells. It binds to the angiotensin-converting enzyme 2 (ACE2) receptor present on the host's cells surface, and the binding affinity is 10-20 times more than SARS-CoV, which might explain its higher transmission rate among humans. After attachment, S protein undergoes conformational changes that help in the fusion of viral and endosomal membranes. The viral RNA is then released into the host cell, and this is facilitated by host transmembrane protease serine-type 2 (TMPRSS2). After entering the cell, the viral RNA gets uncoated and translated into viral polymerase protein. After this, the viral RNA gets replicated using its RNA-dependent RNA polymerase (RdRp). Structural proteins are then synthesized, assembled, and released outside the cell [10]. The various steps involved in the viral lifecycle provide potential targets for drug discovery and facilitates drug repurposing. The promising drug targets are 3-chymotrypsin-like protease (3CLPro) and papain-like protease (proteolysis of viral polyprotein), RdRp (involved in viral replication), $\mathrm{S}$ protein (helps in viral entry by binding to ACE2), and TMPRSS2 (helps in priming of S protein to facilitate its binding to ACE2) [11]. Apart from these, immune regulation and inflammatory pathways, which involve Th-17, interferons, proinflammatory cytokines, lymphocytes as natural killer cells, JAK proteins, and checkpoints such as 
programmed cell death protein 1(PD1), are also targeted in search of the therapeutic molecules for COVID-19. Biologics such as monoclonal antibodies are being developed to target various pathogenic molecules involved in SARSCoV-2 infections. Figure 1 summarizes the life cycle of SARS-CoV-2 and major pharmacologic targets for treatments or adjunctive therapies for COVID-19.

\section{Pipeline Pharmacological Therapies for COVID-19}

Research for testing the safety and efficacy of different types of interventions for COVID-19 is carried out at an exceptional rate. The conventional drug development process is not feasible in the current scenario of the pandemic, so, the majority of studies in clinical trials for COVID-19 include the drugs already in use for other diseases. Various classes of drugs including antivirals, immunomodulators, anti-inflammatory drugs, corticosteroids, antibiotics, and traditional Chinese medicine have been investigated so far in search of new treatment avenues or interventions to combat COVID-19. Among them, remdesivir, convalescent plasma, anti-inflammatory drugs like interleukin-6 (IL-6) inhibitors (tocilizumab and sarilumab), and traditional Chinese medicines prove to be the most promising therapies [12]. Apart from various antivirals, immunomodulators, and IL-6 inhibitors, the current emerging therapies focus on cell-based therapy (natural killer (NK) cells and mesenchymal stem cells), biologics (monoclonal antibodies, interleukins, cytokines), ACE2 receptor blocker, angiotensin II type I receptor blockers (ARB), fibrinolytic therapy, and combination therapy of various antivirals

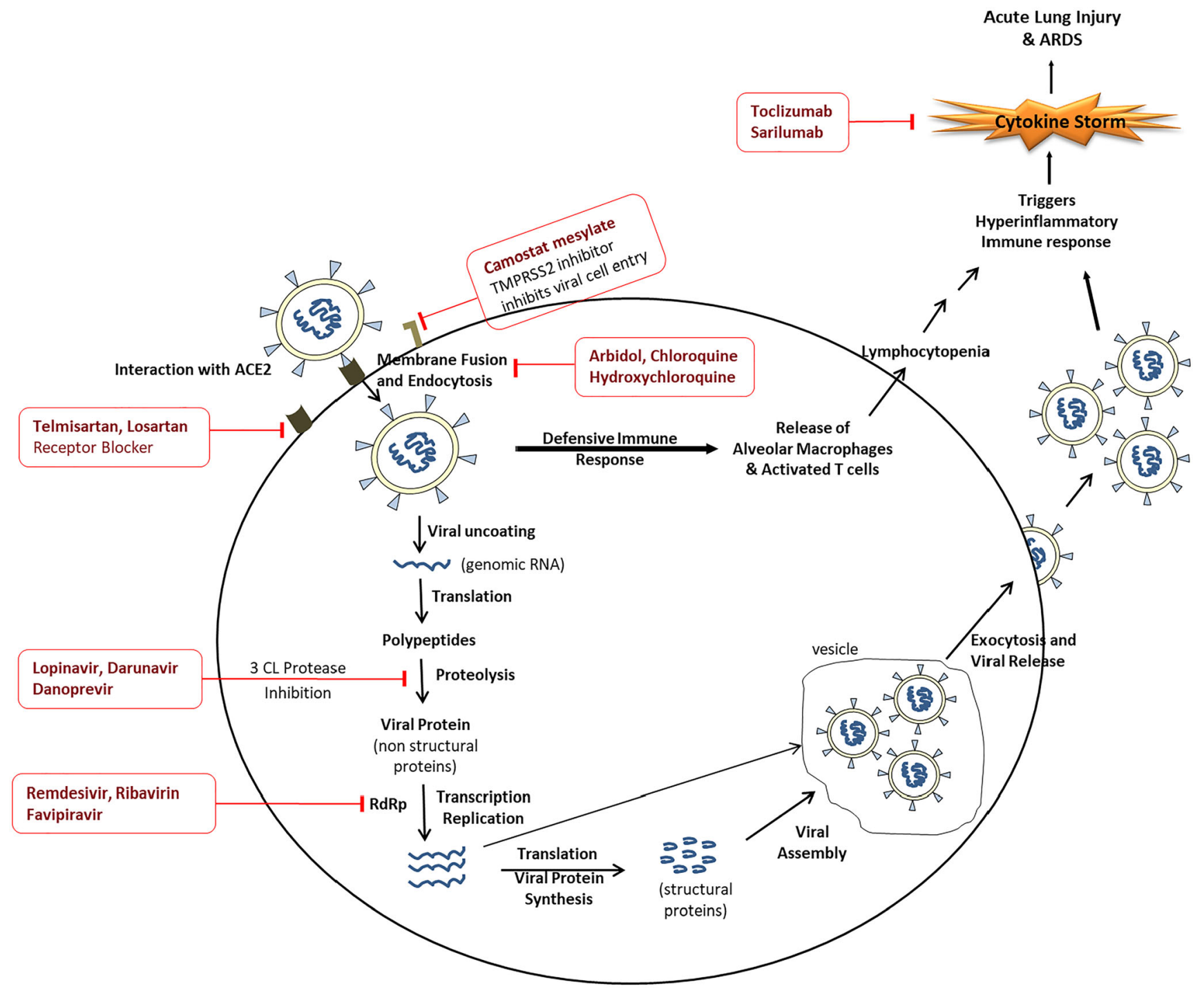

Fig. 1 Life cycle of SARS-CoV-2 and targets for drug development for COVID-19. ACE2 angiotensin converting enzyme 2, TMPRSS2 transmembrane protease serine type 2, RdRp RNA-dependent RNA polymerase, 3CLPro 3-chymotrypsin-like protease, ARDS acute respiratory distress syndrome 
with immunomodulators, antibiotics, nonsteroidal antiinflammatory drug (NSAIDs), etc.

To combat various comorbidities associated with COVID19, many conventional antidiabetic (sitagliptin, dapagliflozin), antihypertensive (ramipril, prazosin, amiodarone, spironolactone), and lipid lowering agents (atorvastatin) have been studied in clinical trials along with standard treatment regimen. Various antineoplastic drugs (etoposide, methotrexate, melphalan, isotretinoin plus tamoxifen, nintedanib, lenalidomide, etc.) and drugs like thalidomide, oxytocin, chlorpromazine, montelukast, povidone-iodine, famotidine, cholecalciferol, $\mathrm{N}$-acetylcysteine, and pyridostigmine bromide have also been studied in clinical trials for COVID-19. To address the respiratory distress associated with COVID-19, the role of drugs like valsartan and sirolimus is being investigated in various clinical trials. There is an emerging role of recombinant bacterial ACE2 receptors like the enzyme of $\mathrm{B} 38$-CAP (rbACE2) for COVID-19. It works like human-ACE2 and decreases angiotensin II level, thereby reducing the release of proinflammatory cytokines and the development of ARDS. It has been proposed that due to bacterial origin, it might not get recognized by SARS-CoV-2 spike protein and hence possess added advantage over conventional ACE2 inhibitors (ACEI) and ARBs. However, it is yet to determine whether long-term use of ACEI, ARBs, and rbACE2 will increase or alleviate the SARS-CoV-2 infection.

Another approach for reducing the impact of COVID-19 pandemic is to develop COVID-19 vaccines that can be available to people across the globe. Many vaccines are being studied in animal models, and some of them have entered the clinical trials. However, months are needed before the vaccines are developed, approved, and marketed. Some researchers and clinicians have proposed the role of bacillus Calmette Guérin (BCG) vaccines, levamisole, and Isoprinosine, as prophylactic therapy for COVID-19. BCG vaccine is assumed to enhance the innate immune response by inducing metabolic and epigenetic changes. Clinical trials are underway in Australia and Netherlands for determining the efficacy of BCG vaccines in healthcare workers, while some recent studies do not favor the role of BCG vaccine in COVID-19. As of July 4, more than 900 interventional trials have been registered to ClinicalTrials.gov targeting pharmacological drugs for COVID-19 [13]. Table 1 enlists some of the potential pipeline drugs currently being studied or are registered in the clinical trials for evaluating their efficacy for COVD-19. Some natural products, Ayurvedic and herbal medicines, and traditional Chinese medicines are also being studied in the clinical trials owing to their known and established immunomodulatory and anti-viral effects. Table 2 comprises the list of natural products under clinical trials for COVID-19.
Promising Drugs for COVID-19: Current Status and Future Directions

\section{Antiviral Drugs}

Remdesivir (GS-5734) It is an investigational nucleotide adenosine analog developed by Gilead Sciences, USA, and is a monophosphoramidate prodrug of remdesivir-triphosphate. It has shown broad-spectrum antiviral activity against filoviruses, paramyxoviruses, pneumoviruses, and many animal and human coronaviruses including SARS and MERS [14-16]. Also, it was well tolerated in a phase 3 study for the treatment of EBOLA virus disease [17]. Currently, remdesivir is one of the most promising drugs under trial and is the center of attention for the treatment of COVID-19. It acts as an RdRp inhibitor and blocks viral RNA replication [18]. It has shown its therapeutic potential against SARSCoV-2 in various in vitro and animal studies $[19,20]$. The published report of treatment of first COVID-19 patients in the USA and remdesivir's use in a 53-patient case series have also documented the efficacy of remdesivir for COVID-19 patients [21, 22]. But, a recently published report of a randomized, double-blind, placebo-controlled, multicentre trial at ten hospitals in Hubei, China, has documented the statistically non-significant clinical benefits in the remdesivir group, although the numerical reduction in time to clinical improvement in those treated earlier was numerically shorter in the remdesivir group than the control group [23]. The dose used in this study was a single 200-mg loading dose, followed by a 100-mg daily infusion, and the most common adverse events seen in the remdesivir group were constipation, hypoalbuminemia, hypokalemia, anemia, thrombocytopenia, and increased total bilirubin. Moreover, the preliminary report of a doubleblind, randomized, placebo-controlled trial of remdesivir in 1059 hospitalized COVID-19 patients (538 in remdesivir and 521 in the placebo group) has reported that remdesivir was superior to placebo in shortening the time to recovery in COVID-19 patients. In this study, remdesivir was administered intravenously at $200 \mathrm{mg}$ loading dose on day 1 and $100 \mathrm{mg}$ daily from day 2 to day 10 [24]. Another randomized, open-label, phase 3 trial in 397 (200 patients for 5 days and 197 for 10 days) COVID-19 patients not requiring mechanical ventilation has reported no significant difference between a 5day course and a 10-day course of remdesivir. All the patients received $200 \mathrm{mg}$ of intravenous remdesivir on day 1 and $100 \mathrm{mg}$ once daily on subsequent days. The limitation of this study was the open-label design and the absence of a placebo control group [25]. However, whether remdesivir is associated with more benefit or might cause harm needs to be confirmed in a randomized control trial (RCT) of a larger sample size. Fortunately, above 20 randomized trials involving remdesivir are registered on ClinicalTrials.gov and are recruiting participants globally [13]. Recently, remdesivir is certified 
Table 1 List of pipeline drugs currently studied/registered in the clinical trial for COVID-19

\begin{tabular}{llll}
\hline $\begin{array}{l}\text { Drugs/Drug combinations } \\
\text { (Classification) }\end{array}$ & $\begin{array}{l}\text { Stage of } \\
\text { development }\end{array}$ & $\begin{array}{l}\text { Targets and possible mechanism } \\
\text { of action for use in COVID-19 }\end{array}$ & $\begin{array}{l}\text { Disease indication } \\
\text { (Approved/Investigational)* }\end{array}$ \\
\hline
\end{tabular}

$\begin{array}{ccc}\begin{array}{c}\text { Remdesivir (antiviral, adenosine } \\ \text { nucleotide analog) }\end{array} & \text { Phase 2/3 } & \begin{array}{c}\text { Target RdRp and inhibit it, thereby inhibiting } \\ \text { viral replication and viral RNA synthesis }\end{array}\end{array}$

Favipiravir (antiviral, purine nucleoside Phase 2/3/4 analog)

Ribavirin (antiviral, guanine nucleotide Phase 1/2 analog)

Galidesivir (antiviral, adenosine nucleoside analog)

Lopinavir/Ritonavir (increases oral bioavailability of lopinavir) (antiviral, protease inhibitor)

Darunavir (antiviral, protease inhibitor) Phase 1 and Cobicistat (Pharmacokinetic enhancer)

Umifenovir or Arbidol (antiviral, fusion inhibitor)

Danoprevir (antiviral, protease inhibitor)

Oseltamivir (antiviral, Neuraminidase inhibitor)

Camostat Mesylate (serine protease inhibitor)

Clevudine (synthetic pyrimidine analog)

Chloroquine and hydroxychloroquine (antimalarial, aminoquinolone derivative, antiviral and immunomodulatory properties)

Interferon-beta $1 \mathrm{a}$ and $1 \mathrm{~b}$ (antiviral and immunomodulators, protein-based therapy)

Peginterferon lambda-1a (antiviral and immunomodulators, protein-based therapy)

Convalescent plasma/hyperimmune plasma (passive Immunotherapy)

\footnotetext{
Anakinra (recombinant interleukin, immunotherapy)
} Tocilizumab (recombinant humanized
monoclonal antibody)

Sarilumab (monoclonal antibody)

Natural killer cells (biologicals)
Target RdRp and inhibits viral RNA synthesis

Target RdRp and inhibits viral RNA synthesis and mRNA capping

Phase 1

Target and bind to viral RNA polymerase, premature termination of the elongating RNA strand

Phase 2/3 Target protease enzyme, inhibits protein cleavage and halt virus maturation

Target protease enzyme, inhibits protein cleavage and halt virus maturation (decrease viral load and increase CD4 cell counts)

Phase 4

Inhibits fusion between viral and cellular membrane

Phase 4 Target protease, Inhibits viral replication

Phase 2/3/4 Target neuraminidase enzyme, inhibits viral entry, replication and its release

Phase 2 Target TMPRSS2, inhibits its action and thereby inhibits viral entry to cells

Phase 2 Target DNA polymerase and reverse transcriptase enzyme, block viral replication and the supply of viral DNA into the nucleus

Phase 2/3/4 Changes the $\mathrm{pH}$ of endosomes and inhibit ACE2 glycosylation, prevent viral entry, transport and, post-entry events

Phase 2/4 (1a) Target type 1 interferon receptors, Activate Phase 2 (for

Phase 2

Phase $1 / 2 / 3 \quad$ Plasma from persons who have survived JAK/STAT and stimulate innate antiviral immunity, also changes the expression of cytokine and matrix metalloproteinase

Stimulate innate antiviral immunity COVID-19 might contain antibodies (IgG, $\operatorname{IgA}, \operatorname{IgM}, \operatorname{IgE}$, and $\operatorname{IgD}$ ) of human origin as a result of developed humoral immunity to SARS-CoV-2 and can be used to reduce the viral load and disease mortality in other patients

Phase 2/3

Target Interleukin-1 type I receptor (IL-1RI), and acts as an IL-1 receptor antagonist, also block IL-18 production

Phase $2 / 3$

IL-6 inhibitor, block cytokine storm

Phase $2 / 3$

IL-6 inhibitor, blocks cytokine storm

Phase $1 / 2$
Innate lymphocytes that act via the process of antibody-dependent cellular cytotoxicity, possess antiviral effect
Investigational drug for Ebola virus and variety of RNA viruses;

FDA Emergency Use Authorization against COVID-19

Approved to treat influenza in Japan

Chronic hepatitis $\mathrm{C}$ virus (HCV) infection

Investigational drug for Ebola, Marburg, Yellow Fever and Zika viruses

Approved for HIV-1 infection

Approved as second- generation protease inhibitors for HIV infection

Approved in Russia and China for the prophylaxis and treatment of influenza $\mathrm{A}, \mathrm{B}$, and other arboviruses

Investigational drug for chronic hepatitis $\mathrm{C}$ patients

Approved for prophylaxis and treatment of influenza A (including H1N1) and B

Approved in Japan for chronic pancreatitis and drug-induced lung injury

Investigational drug for hepatitis B

Antimalarial drugs, also used for systemic lupus erythematosus; acute and chronic rheumatoid arthritis

Relapsing remitting multiple sclerosis (RRMS)

Investigational long acting drug for hepatitis $\mathrm{C}$

Investigational approach tried for emerging Infectious Diseases like Ebola virus

Rheumatoid arthritis and neonatal-onset multisystem inflammatory disease

Rheumatoid and giant cell arthritis, polyarticular and systemic juvenile idiopathic arthritis, cytokine release syndrome

Moderate to severe reactive Rheumatoid Arthritis

Cancer immunotherapy 
Table 1 (continued)

Drugs/Drug combinations (Classification)

Stem cell therapy (biologicals)

Fingolimod (immunomodulator; sphingosine-1-phosphate receptor regulators)

Bevacizumab (recombinant humanized Phase 3 monoclonal antibody, VEGF inhibitor)

Baricitinib (kinase inhibitor)

Phase 2/3

Ruxolitinib (kinase inhibitor)

Phase $1 / 2 / 3$

Acalabrutinib (kinase inhibitor)

Phase 2

CD24Fc (biological immunomodulatory, comprises the nonpolymorphic regions of CD24 attached to the $\mathrm{Fc}$ region of human IgG1)

Thymosin (PD1 blocking monoclonal antibody)

Tradipitant (neurokinin-1 (NK1)

Phase 3

Eculizumab (monoclonal antibody, terminal complement inhibitor)

Phase 2

Sargramostim (recombinant humanized Phase 4 granulocyte-macrophage colony stimulating factor (rhuGM-CSF))

Aviptadil (vasoactive intestinal polypeptide)

Phase 2/3 Telmisartan, Losartan (angiotensin II
receptor blocker)

Isotretinoin (retinoid derivative of vitamin $\mathrm{A}$ )

Naproxen (anti-inflammatory) (studied Phase 3 in combination with antiviral)

Phase $2 / 3$

Phase $2 / 3$

Phase 2/3/4 losartan)

Phase $1 / 3$
Targets and possible mechanism

of action for use in COVID-19

Mesenchymal stem cells (MSCs) have high regenerative and immunomodulatory capacities. These modulate the inflammatory response, boost tissue repair, enhance pathogen clearance, and reduce the severity of the injury, pulmonary dysfunction, and apoptosis.

Binds to Sphingosine-1-phosphate receptor and acts as a functional antagonist and reduces lung inflammation

Target vascular endothelial growth factor (VEGF), inhibit it and prevents acute lung injury (ALI) and ARDS

Target PD-1 receptor expressed on the surface of $\mathrm{T}$ cells and regulate cellular immunity by blocking the activity of PD-1 (immune check pathway), prevent $\mathrm{T}$ cell death and regulate cytokine production

NK1 receptor antagonist; works by blocking substance $\mathrm{P}$, reduces inflammatory lung injury and relieves chronic cough

Target complement protein C5, prevents activation of a complement terminal complex and immune-mediated inflammation

Target GMCSF, a pleiotropic cytokine and stimulates JAK2 STAT1/STAT3 signal transduction pathway, pivotal function in hematopoiesis and cell-mediated immunity.

Prevents NMDA-induced caspase-3 activation in Approved in Europe for, erectile the lung, inhibits IL- 6 and TNF $\alpha$ production and restores barrier function at the endothelial/alveolar interface (one phase 1 study for

Target angiotensin II type 1 (AT1) receptors, degrade angiotensin II to angiotensin 1-7, reduces inflammation and release of proinflammatory cytokines thereby reduces chances of ARDS

Strongest down-regulation of ACE 2 receptors also inhibit potential papain-like protease (PLpro), which is a protein encoded by SARS-CoV-2 genes

Disease indication
(Approved/Investigational)*

Several carcinomas, inherited metabolic disorders, myelodysplastic syndromes, lymphomas, leukemias, other disorders of blood cell proliferation, inherited disorders affecting the immune system and other organs

Relapsing remitting multiple sclerosis (RRMS)

Metastatic colorectal cancer, metastatic and recurrent non-squamous non-small cell lung cancer, metastatic renal cell carcinoma, recurrent cervical cancer, epithelial ovarian cancer etc.

Rheumatoid arthritis in adult patients

Intermediate or high-risk myelofibrosis

Chronic lymphocytic leukemia or small lymphocytic lymphoma

Investigational biologics to inhibit multiple inflammatory cytokines

An investigational drug in trials of eczema, pruritus, gastroparesis, chronic pruritus, atopic dermatitis

Paroxysmal nocturnal hemoglobinuria

Cancer and bone marrow transplant dysfunction, FDA orphan drug designation for treating ARDS

Hypertension; diabetic nephropathy in hypertensive patients with type 2 diabetes mellitus; congestive heart failure

Severe recalcitrant nodular acne

Osteoarthritis, rheumatoid arthritis, acute gouty arthritis, primary dysmenorrhea, 
Table 1 (continued)

\begin{tabular}{|c|c|c|c|}
\hline $\begin{array}{l}\text { Drugs/Drug combinations } \\
\text { (Classification) }\end{array}$ & $\begin{array}{l}\text { Stage of } \\
\text { development }\end{array}$ & $\begin{array}{l}\text { Targets and possible mechanism } \\
\text { of action for use in COVID-19 }\end{array}$ & $\begin{array}{l}\text { Disease indication } \\
\text { (Approved/Investigational)* }^{*}\end{array}$ \\
\hline & & $\begin{array}{l}\text { Inhibit cyclo-oxygenase } 2 \text { (COX-2) and } \\
\text { Influenza A virus nucleoprotein (NP), reduces } \\
\text { inflammation }\end{array}$ & $\begin{array}{l}\text { for inflammation and pain in } \\
\text { musculoskeletal }\end{array}$ \\
\hline $\begin{array}{l}\text { Azithromycin (broad-spectrum } \\
\text { macrolide antibiotic (studied alone or } \\
\text { in combination with } \\
\text { hydroxychloroquine or } \\
\text { amoxicillin/clavulanic acid)) }\end{array}$ & Phase $2 / 3 / 4$ & $\begin{array}{l}\text { Target bacterial ribosomes, inhibits } \\
\text { transpeptidation and stops protein synthesis, } \\
\text { also have immunomodulatory effects, which } \\
\text { might decrease respiratory inflammation }\end{array}$ & $\begin{array}{l}\text { Respiratory, enteric and genitourinary } \\
\text { infections; some sexually transmitted } \\
\text { and enteric infections, infections caused } \\
\text { by susceptible strains of the } \\
\text { microorganisms listed by FDA; }\end{array}$ \\
\hline $\begin{array}{l}\text { Nitazoxanide (antiviral and } \\
\text { antiprotozoal, studied in combination } \\
\text { with hydroxychloroquine, or other } \\
\text { drugs) }\end{array}$ & Phase $2 / 3$ & $\begin{array}{l}\text { Targets viral hemagglutinin and the viral } \\
\text { transcription factor, inhibits viral replication, } \\
\text { possess anti-cytokine and autophagy } \\
\text { properties }\end{array}$ & diarrhea in adults and children \\
\hline $\begin{array}{l}\text { Colchicine (alkaloids, } \\
\text { anti-inflammatory drug) }\end{array}$ & Phase $2 / 3$ & $\begin{array}{l}\text { Targets inflammasome complex, inhibits } \\
\text { microtubules polymerization and production } \\
\text { of IL-1 } 1 \beta \text { and IL-6, prevents cytokine storm }\end{array}$ & Gout and familial Mediterranean fever \\
\hline Deferoxamine (iron chelator) & Phase $1 / 2 / 3$ & $\begin{array}{l}\text { Manages excess iron levels in the blood, prevents } \\
\text { iron toxicity and hence prevents severe } \\
\text { respiratory manifestations and inflammation in } \\
\text { the alveoli }\end{array}$ & $\begin{array}{l}\text { Acute iron or aluminum toxicity; anemia } \\
\text { in patients who must receive many } \\
\text { blood transfusions }\end{array}$ \\
\hline $\begin{array}{l}\text { Heparin (enoxaparin), Tinzaparin or } \\
\text { unfractionated heparin } \\
\text { (anticoagulant) }\end{array}$ & Phase 2/3/4 & $\begin{array}{l}\text { Inhibit coagulation factor Xa and thrombin by } \\
\text { binding to the plasma protease inhibitor, } \\
\text { prevents venous thromboembolism in } \\
\text { COVID-19 patients }\end{array}$ & $\begin{array}{l}\text { Prevention of postoperative venous } \\
\text { thromboembolism; deep vein } \\
\text { thrombosis and/or pulmonary } \\
\text { embolism; prevention of clot formation } \\
\text { in indwelling intravenous lines for } \\
\text { hemodialysis }\end{array}$ \\
\hline $\begin{array}{l}\text { Inhaled nitric oxide (INO) } \\
\text { (pulmonary vasodilator) }\end{array}$ & Phase $1 / 2$ & $\begin{array}{l}\text { Targets heme molecule of cytosolic guanylate } \\
\text { cyclase and results in pulmonary vasodilation, } \\
\text { early administration might prevent cases of } \\
\text { respiratory failure in COVID-19, also act as } \\
\text { anti-thrombotic in lung }\end{array}$ & Hypoxic respiratory failure in neonates \\
\hline $\begin{array}{l}\text { Ascorbic acid (nutraceutical, } \\
\text { antioxidant) }\end{array}$ & Phase $1 / 2 / 3$ & $\begin{array}{l}\text { Targets the dysregulated immune response, } \\
\text { increase the activity of lymphocytes, reduce } \\
\text { the risk of development of inflammatory } \\
\text { markers, ARDS and respiratory failure }\end{array}$ & $\begin{array}{l}\text { Approved for scurvy, delayed wound and } \\
\text { bone healing, urine acidification. } \\
\text { Investigational drug for sepsis, acute lung } \\
\text { injury (ALI) }\end{array}$ \\
\hline
\end{tabular}

*All drugs mentioned here are investigational drugs for COVID-19; however, they might be approved for some other disease indications

Table 2 List of natural products under clinical trials for COVID-19

\begin{tabular}{|c|c|c|}
\hline Natural products & Stage of development & $\begin{array}{l}\text { Classification/Possible mechanism of action for use } \\
\text { in COVID-19 }\end{array}$ \\
\hline Açaí Palm Berry extract & Phase 2 & $\begin{array}{l}\text { Potent inhibitor of Nod-like receptor family, } \\
\text { pyrin-containing } 3 \text { (NLRP3) }\end{array}$ \\
\hline Nigella sativa & Phase 2 & Immunomodulator and antiviral \\
\hline Gum Arabic powder & Phase 2 & Immunomodulator and anti-inflammatory agent \\
\hline Natural honey & Phase 3 & $\begin{array}{l}\text { Antibacterial, antifungal, antiviral and } \\
\text { antimycobacterial }\end{array}$ \\
\hline Nigella Sativa and Honey & Phase 3 & Immunomodulator, antibacterial, and antiviral \\
\hline $\begin{array}{l}\text { Artemisinin, Curcumin, Boswellia, and } \\
\text { Vitamin C (ArtemiC) }\end{array}$ & Phase 2 & $\begin{array}{l}\text { Anti-oxidant, anti-inflammatory, and anti-aggregant } \\
\text { and anti-microbial }\end{array}$ \\
\hline $\begin{array}{l}\text { Traditional Chinese medicines (various herbal } \\
\text { products are included in this category) }\end{array}$ & Phase 3 & $\begin{array}{l}\text { Immunomodulatory and anti-inflammatory } \\
\text { mechanisms, decrease the level of cytokines such } \\
\text { as TNF- } \alpha, \mathrm{IL}-1 \beta, \mathrm{IL}-6, \mathrm{IL}-8 \text {, and IL-10, inhibit } \\
\text { lung inflammation or acute lung injury }\end{array}$ \\
\hline
\end{tabular}


for an emergency use authorization (EUA) for treating hospitalized COVID-19 patients by the US Food and Drug Administration (FDA). Promising signals from various studies are available yet more data are needed to conclude its efficacy for COVID-19. The risk-benefit ratio needs to be optimized in a larger population size with an early start of remdesivir treatment in COVID-19 patients. Moreover, the adequate dose should be selected, which produces clinically beneficial effects and causes less harm.

Favipiravir (T-705 or Avigan) It is another most promising purine nucleoside analog being studied for COVID-19 and was developed by Fujifilm Toyama, Japan. It has shown anti-viral activity for various RNA viruses including the Ebola virus and oseltamivir-resistant influenza virus [26]. It is a prodrug of favipiravir ribofuranosy $1-5$ '-triphosphate (favipiravir-RTP) and acts by inhibiting RNA polymerase activity, thus ceasing viral replication [27]. It has been approved in Japan and China for the treatment of novel influenza virus infections, and in March 2020, China has approved its use for COVID-19 patients. A study by Wang et al. has reported the EC50 of favipiravir was $61.88 \mu \mathrm{M} / \mathrm{L}$ against SARS-CoV-2 in Vero E6 cells [19]. A study conducted on COVID-19 patients in China has stated the more potent antiviral action (shorter time for viral clearance) of favipiravir plus interferon-alpha than that of lopinavir/ritonavir plus interferon-alpha [28]. Furthermore, a prospective, multicenter, open-label, randomized trial in China comparing favipiravir with arbidol has shown better recovery profile after 7-day treatment in those on favipiravir among moderately ill patients but not among mildly or severely ill patients [29]. Favipiravir has mutagenic potential and cannot be used in pregnant women, but the main adverse effects reported in previous studies are mild to moderate diarrhea, an asymptomatic increase of blood uric acid and transaminases, and a decrease in the neutrophil counts [30]. To date, more than 25 clinical trials are registered for favipiravir in clinicaltrials. gov. Recently, in India, Glenmark pharmaceuticals got regulatory approval for the manufacturing and marketing of favipiravir (FabiFlu) to treat mild-to-moderate COVID-19 patients. Together, all these data suggest the potential antiviral action of favipiravir on SARS-CoV-2. However, favipiravir has shown a variable range of IC50 in various viral studies, [27] and some studies have documented a possible ethnic or regional difference in its pharmacokinetic [31]. So, before concluding its antiviral effects in COVID-19 patients, it is very important to standardize its dosing regimen in the clinical trial and should consider the pharmacokinetic variations and drugdrug interactions among individuals of a different region.

Lopinavir and Ritonavir These protease inhibitors are widely used for human immunodeficiency virus (HIV) and have also shown potential antiviral activity against SARS-CoV and MERS-CoV in various studies conducted in vitro and in animal $[32,33]$. They are also being studied in clinical trials for COVID-19 and act by inhibiting the 3CLPro enzyme and thereby stop viral protein synthesis [33]. Lopinavir has shown efficacy against the SARS-CoV-2 virus in vitro, but treatment with LPV/RTV alone for 14 days in an open-label RCT of COVID-19 patients $(n=199)$ does not show any difference in clinical improvement as compared with standard of care [34]. But, the adverse effects reported were less including diarrhea, nausea, and asthenia, and the number of death was also less in the LPV/RTV group in comparison to the control group. Recently, a study by Hung et al. has reported better antiviral and safety profiles, and faster recovery rates with early triple antiviral therapy (LPV/RTV, interferon beta-1b, and ribavirin) in comparison with LPV/RTV alone in a phase 2 RCT of COVID-19 patients. [35]. Although, initial results of LPV/ RTV RCT have not shown the remarkable clinical improvement, yet WHO and other organizations are testing the efficacy of LPV/RTV in the clinical trial of COVID-19. The role of LPV/RTV for post-exposure prophylaxis (PEP) to COVID-19 is also being evaluated in one of the registered phase 3 clinical trials. More RCTs with adequate power are required to conclude the efficacy of LPV/RTV in COVID-19 patients.

Chloroquine and Hydroxychloroquine They are aminoquinolines known for their anti-malarial and immunomodulatory effect, and from 2006 they have been established as a wide spectrum antiviral drug [36, 37]. Recently, chloroquine has demonstrated the efficacy against SARS-CoV-2 in Vero E6 cells 19. Being a weak diprotic base both CQ and HCQ act by increasing the $\mathrm{pH}$ of endosomes and prevent the fusion of viral and host cell membrane [38]. They also interfere with the glycosylation of SARS-CoV-2 receptors and also act at the post-entry stage of the virus. A study by Gao and colleagues have indicated the beneficial role of CQ phosphate in reducing the severity of pneumonia and lung injury, thereby decreasing the course of the disease in almost 100 patients of COVID-19 in comparison to the control group [39]. HCQ (EC50= $6.14 \mu \mathrm{M})$ is more potent and safer than CQ (EC50= $23.90 \mu \mathrm{M}$ ) and found to have a role in preventing cytokine storm that occurs in serious cases of COVID-19. An openlabel nonrandomized French study of 36 patients (20 in the HCQ group and 16 in the control group) reported improved viral clearance with HCQ compared with control group patients receiving standard supportive care. The authors also reported that including azithromycin with HCQ for the treatment of 6 patients has shown more improvements in viral clearance in comparison to the HCQ alone group [40]. But, a prospective study of 30 patients in China stated that there was no difference in clinical outcomes between HCQ (400 mg, daily for 5 days) plus standard treatment group (supportive care, interferon, and other antivirals) and standard treatment alone group [41]. At the time, HCQ was the most promising and wonder drug for COVID-19, and now, despite 
initially promising results, recent studies on HCQ have reported disappointing findings so far in the randomized trials [42, 43]. However, WHO and ICMR (Indian council of medical research) still find some hope with $\mathrm{HCQ}$, and trials are being conducted to ascertain its efficacy and safety for COVID-19. In India, HCQ is used as a prophylactic drug for SARS-CoV-2 infection in healthcare professionals. Recently, the results of a most awaited trial conducted in the USA on 96,032 COVID19 patients using HCQ and CQ with or without macrolides have demonstrated no significant differences in the clinical outcome of these agents in comparison to control group [44]. Also, some adverse events were reported with the CQ and HCQ group including arrhythmia and the survival rates were also less in these groups in comparison to the control group. Many RCTs on both CQ and HCQ are still in the clinical trial, evaluating their role against COVID-19 treatment, but whether it is efficacious or not, it would be ascertained only after completion of these trials. Also, it is important to optimize the dose, therapeutic time window, and the risk-benefit ratio associated with the use of HCQ.

\section{Immunomodulators and Biologics}

Convalescent Plasma This passive immunoglobulin therapy is one of the potential adjunctive therapies now being used for COVID-19 patients. The rationale for such passive immunization is that plasma collected from patients after they recovered from COVID-19 might contain antibodies (IgG, IgA, IgM, IgE, and $\mathrm{IgD}$ ) to SARS-CoV-2 and can be used to reduce the viremia and disease mortality in patients with life-threatening SARSCoV-2 infections. Convalescent plasma therapy has been used in the past for many viral infections such as Ebola, influenza, poliomyelitis, SARS, and MERS and has shown improvement in clinical outcome [45-49]. Recently, a case series of 5 critically ill patients with COVID-19 treated with convalescent plasma was published, in which they have demonstrated the improvement in clinical symptoms including a reduction in viral load [50]. Also, improvement in clinical outcomes was seen in 300 COVID-19 patients treated with convalescent plasma along with standard treatment in a clinical trial conducted in China (ChiCTR2000029757) [51]. These data support the utility of convalescent plasma therapy for COVID-19 patients, yet its use, until now, is recommended only to severe patients with life-threatening COVID-19 infections. More RCTs are required to optimize the amount, timing, and duration for which it is to be administered to COVID-19 patients. Moreover, being a polyclonal antibody therapy, its efficacy on the long run should be investigated more.

Antibody-Based Therapies Biologics such as monoclonal antibodies are being developed as targeted specific therapeutic agents for SARS-CoV-2 infections. The receptor-binding domain (RBD) in spike protein is the key target of neutralizing monoclonal antibodies [52]. Moreover, cytokine storm (CS), i.e., uncontrolled release of pro-inflammatory cytokines has been reported to correlate with disease severity in SARSCoV-2 infection, and it might lead to acute lung injury, acute respiratory distress syndrome (ARDS), and death [53, 54]. Several reports have confirmed that patients admitted to an ICU had higher concentrations of proinflammatory cytokines, particularly IL-6 [55-57]. Therefore, targeting IL-6 and its receptor (IL6R) by tocilizumab and siltuximab monoclonal antibodies could mitigate cytokine storm-related symptoms in severe COVID-19 patients [58]. Tocilizumab and Sarilumab are IL-6 receptor antagonists and proposed to be beneficial in preventing cytokine storms involved in COVID19 pathogenesis. These recombinant human monoclonal antibodies are indicated for rheumatoid arthritis (RA). Till now, several clinical trials of tocilizumab and sarilumab, alone or in combination with other drugs, have been registered in patients with COVID-19 with severe pneumonia [13]. In a retrospective study in China, the administration of $400 \mathrm{mg}$ of tocilizumab to 21 patients with COVID-19 has shown improvement in clinical outcomes such as improved respiratory function in $91 \%$ of patients [59]. Also, sarilumab is studied in a multicenter, double-blind, phase $2 / 3$ trial for hospitalized patients with severe COVID-19. Their safety and efficacy in COVID-19 patients will only be established after the completion of the ongoing clinical trials. However, a recent openlabel phase 2 trial (NCT04346355) conducted in the Italy was stopped early because of lack of benefit of tocilizumab in COVID-19 patients. So, more trials with adequate sample size and design are needed to confirm or deny the efficacy of tocilizumab in COVID-19 patients.

\section{Cell-Based Therapies (NK Cells and Mesenchymal Stem Cells)} Cell-based therapies have now been proposed as a prudent therapy against COVID-19. It works by boosting the immunity of SARS-CoV-2 patients. Recently, the FDA has approved Celularity to start a clinical trial for COVID-19 using natural killer (NK) cells (CYNK-001), which is used earlier in small numbers of cancer patients and found safe. CYNK-001 is a cryopreserved allogeneic natural killer cell therapy derived from placental hematopoietic stem cells. NK cells are important immune cells necessary for defense against virus-infected cells and neoplastic cells and show their activity via the process of antibody-dependent cellular cytotoxicity (ADCC) [60]. Moreover, studies have reported that NK cells can exert antiviral activity against SARS, herpes simplex virus type 1 (HSV-1), cytomegalovirus (CMV), and HIV [61-63]. As the number of NK cells is reduced in severe COVID-19 patients, so it will be prudent to give NK cell therapy to COVID-19 patients to increase the ability to fight to SARS-CoV-2 infection.

Another cell-based therapy that has shown promising results in COVID-19 is mesenchymal stem cell (MSC) transfusion. Various studies have shown the anti-inflammatory and 
immunomodulatory role of MSCs and their ability to alleviate lung injury and ARDS [64-66]. Recently, a pilot study conducted in China on seven COVID-19 patients, who had received intravenous infusions of donor mesenchymal stem cells (multipotent cells thought to have immunomodulatory capacities), has reported the recovery of all seven patients and has shown improvement in the clinical outcome [67]. They said that the intervention was safe and might help improve patient outcomes on further use. Also, on April 5, 2020, the US FDA has approved mesenchymal stem cell (MSC) treatments for use in the serious COVID-19 patients. Although, the rationale of using MSC is not very clear and it is said that this therapy might help combat the cytokine storm reported in COVID-19 patients and hence prevents the progression of the disease and reduces mortality. However, more clinical trials with a larger number of patients are required to establish its role in COVID-19.

\section{Traditional Chinese Medicines}

Based on the pivotal role of traditional Chinese medicines (TCM) in the treatment or prevention of many viral infections including influenza, SARS, and MERS, the application of TCM as adjuvant therapy in COVID-19 patients is highly encouraged [68]. TCM has demonstrated a wide range of mechanisms that includes inhibition of 3CLpro protein (Chinese Rhubarb extracts, Houttuynia cordata extract, hesperetin, etc.), inhibition of RdRp, and inhibition of inflammatory cytokines like TNF- $\alpha$, IL-1 $\beta$, and IL-6 (Fructus Forsythiae), thereby decreasing the severity and mortality rate of the disease [69]. In a molecular docking study by Chen and Du, five herbal compounds including scutellarin, baicalin, hesperetin, nicotianamine, and glycyrrhizin have shown potential in targeting the ACE2 receptor and exerting an antiviral effect to prevent SARS-CoV-2 infection [70]. Medical institutions in China have published many TCM prescriptions, and guideline in China (The Novel Coronavirus Pneumonia Diagnosis and Treatment Plan, 6th trial version) has also suggested the use of a decoction of herbal medicines for lung clearing and detoxification in the clinical treatment [69]. On February 17, The National Health Commission (NHC) of China has reported the beneficial effect of TCM in around more than 60,000 COVID-19 patients. To date, more than 50 clinical trials have registered in China for the evaluation of TCM in COVID-19. Luo, et al. has shortlisted ten most commonly used TCM in China, and they are Astragalus membranaceus, Glycyrrhizae uralensis, Saposhnikoviae divaricata, Rhizoma Atractylodis, Macrocephalae, Lonicerae Japonicae Flos, Fructus forsythia, Atractylodis Rhizoma, Radix platycodonis, Agastache rugosa, and Cyrtomium fortune J. Sm [71]. Although shreds of evidence are available for the efficacy of TCM in COVID-19 patients, yet randomized clinical trials in larger populations are required to evaluate the efficacy and safety of TCM in COVID-19 patients.

\section{Natural Products and Herbal Medicines}

Natural products, purified herbal medicines, and Ayurvedic medicines are known to boost the immunity and have shown the efficacy against many viral infections, including influenza virus, HIV, and SARS-CoV [72, 73]. These herbs either alone or in combination are used for centuries in both Ayurveda and alternative medicine and have proven their efficacy when subjected to rigorous scientific investigation. Also, they play a major role in the discovery and development of many anti-viral drugs based on their structural moiety, classical example being emetine, and quinine [74]. WHO also supports and welcomes innovations around the world regarding scientifically proven traditional medicine. Recently, a study by Rajkumar et.al has highlighted the possible role of Ayurveda in the treatment of COVID-19 through psychoneuroimmune pathways [75]. Several compounds known for their potential immunomodulatory activity such as Withania somnifera (Ashwagandha), Tinospora cordifolia (Guduchi), Asparagus racemosus (Shatavari), Phylanthus embelica (Amalaki), and Glyceriza glabra (Yashtimadhu) might be considered for prophylaxis and as an add-on treatment for COVID-19 [76, 77]. Many medicinal compounds and natural products have exhibited several antiviral mechanisms against SARS-CoV, such as inhibiting the viral 3CL protease and blocking the viral RNA-dependent RNA polymerase activity thereby preventing the early stage of infection, including viral attachment and penetration [72, 74]. Several drugs such as Nigella sativa, natural honey, artemisinin, curcumin, Boswellia, and vitamin $\mathrm{C}$ are in a clinical trial for COVID-19 [13]. Although these natural products and Ayurvedic medicines are studied against coronaviruses including SARS-CoV-2, further studies and clinical trials are needed to establish their role in COVID-19. However, certain challenges like shortage of fundings, lack of patentability, manufacturing difficulties, contamination, lack of product consistency and regulatory measures need to be addressed to market natural products and herbal medicines.

\section{Concluding Remarks}

COVID-19 is continued to be a threat to public health and presents a global challenge to all the research communities around the world to get over from this crisis. Although many compounds have been tested in both non-clinical (simulations, in vitro, and studies in animals) and clinical settings, but unfortunately, there are no FDA-approved vaccines and specific therapeutic interventions for COVID-19 to date. Several strategies have been employed to target the COVID-19 treatment regimen, and three major strategies that are targeted nowadays are repurposing drugs, investigating the efficacy of antibodies, and developing vaccines. Clinical trials are underway in search of a targeted and efficacious treatment for COVID-19; however, 
certain barriers have limited the results of previous trials, and these need to be addressed for getting a more reliable and conclusive outcome. The four major issues that need to be pondered upon to avoid the inconclusive results from previous trials are dose optimization, well-defined therapeutic timing window, trial designs (randomized and adequate powered), and selection of specific outcome measures. Further, there is a need for international collaborative work to fight this pandemic and develop a more robust infrastructure to mitigate the COVID-19 pandemic. Also, innovative computational-based methods like artificial intelligence should be applied to accelerate the traditional drug discovery process, so that this can reduce the total time taken and could be helpful in faster development of drugs during any emergency conditions or pandemic. Keeping in view the emergence of novel life-threatening diseases from mutating RNA viruses with a potential of cross-species transmission, there is a need for a broad-spectrum antiviral agent that could effectively reduce the viral load targeting a wide group of viruses and helps in reducing the massive consequences on human health. Further, we recommend the use of combination therapy that includes both antivirals and non-antiviral regimens to combat both viremia and associated immunopathological symptoms like lymphocytopenia and cytokine storm that might lead to acute lung injury and respiratory failure. Also, emphasis should be given to the rational and adequate use of drugs to prevent the resistance, which is quite common with these mutating RNA viruses. Moreover, the heritage of traditionally used medicinal and herbal compounds should be explored more and needs to be validated via clinical trials, so that their clinical efficacy could be established and would help provide protection for any epidemics like COVID-19. Finally, we hope that the current ongoing efforts will be successful and sooner the drugs and vaccines for COVID-19 will be available, and the world will emerge with better and robust infrastructure, funding, and regulatory measures to combat such future pandemics.

\section{Compliance with Ethical Standards}

Conflict of Interest The authors do not disclose any conflict of interest.

Human and Animal Rights and Informed Consent This article does not contain any studies with human or animal subjects performed by any of the authors.

\section{References}

1. Zhu N, Zhang D, Wang W, Li X, Yang B, Song J, et al. A novel coronavirus from patients with pneumonia in China, 2019. N Engl J Med. 2020;382:727-33.

2. World Health Organisation. WHO Coronavirus Disease (COVID19) Dashboard [Internet]. Available from: https://covid19.who.int/. Accessed 4th July 2020. 2020.
3. Zhou P, Lou YX, Wang XG, Hu B, Zhang L, Zhang W, et al. A pneumonia outbreak associated with a new coronavirus of probable bat origin. Nature. Springer US. 2020;579:270-3.

4. Gorbalenya AE, Baker SC, Baric RS, de Groot RJ, Drosten C, Gulyaeva AA, et al. The species severe acute respiratory syndrome-related coronavirus: classifying 2019-nCoV and naming it SARS-CoV-2. Nat Microbiol. 2020;5:536-44.

5. World Health Organisation. WHO announces COVID-19 outbreak a pandemic [Internet].. Available from: http://www.euro.who.int/ en/health-topics/health-emergencies/coronavirus-covid-19/news/ news/2020/3/who-announces-covid-19-outbreak-a-pandemic. Accessed 14 May 2020. 2020.

6. Zhang W, Zhao Y, Zhang F, Wang Q, Li T, Liu Z, et al. The use of anti-inflammatory drugs in the treatment of people with severe coronavirus disease 2019 (COVID-19): the experience of clinical immunologists from China. Clin Immunol. 2020;214:1-5.

7. Drosten C, Günther S, Preiser W, Van der Werf S, Brodt HR, Becker $S$, et al. Identification of a novel coronavirus in patients with severe acute respiratory syndrome. N Engl J Med. 2003;348:196776.

8. Zaki AM, Van Boheemen S, Bestebroer TM, Osterhaus ADME, Fouchier RAM. Isolation of a novel coronavirus from a man with pneumonia in Saudi Arabia. N Engl J Med. 2012;367:1814-20.

9. Chan JFW, Kok KH, Zhu Z, Chu H, To KKW, Yuan S, et al. Genomic characterization of the 2019 novel human-pathogenic coronavirus isolated from a patient with atypical pneumonia after visiting Wuhan. Emerg Microbes Infect. 2020;9:221-36.

10. Jiang S, Hillyer C, Du L. Neutralizing antibodies against SARSCoV-2 and other human coronaviruses. Trends Immunol. The Author(s). 2020;41:355-9.

11. Liu C, Zhou Q, Li Y, Garner LV, Watkins SP, Carter LJ, et al. Research and development on therapeutic agents and vaccines for COVID-19 and related human coronavirus diseases. ACS Cent Sci. 2020;6:315-31.

12. Thorlund K, Dron L, Park J, Hsu G, Forrest JI, Mills EJ. A real-time dashboard of clinical trials for COVID-19. Lancet Digit Health. 2020;7500:2019-20.

13. ClinicalTrials.gov. Interventional studies for COVID-19. Accessed 4th July 2020. 2020.

14. Lo MK, Jordan R, Arvey A, Sudhamsu J, Shrivastava P, Hotard AL, et al. GS-5734 and its parent nucleoside analog inhibit filo- , pneumo-, and paramyxoviruses. Sci Rep. 2017;7:1-7.

15. Sheahan TP, Sims AC, Graham RL, Menachery VD, Lisa E, Case $\mathrm{JB}$, et al. Broad-spectrum antiviral GS-5734 inhibits both epidemic and zoonotic coronaviruses. Sci Transl Med. 2017;9:1-20.

16. De Wit E, Feldmann F, Cronin J, Jordan R, Okumura A, Thomas T. Prophylactic and therapeutic remdesivir (GS-5734) treatment in the rhesus macaque model of MERS-CoV infection. Proc Natl Acad Sci. 2020;117:6771-6.

17. Proschan M, Ph D, Mukadi D, Manzo ML, Ph D, Nzolo D, et al. A randomized, controlled trial of Ebola virus disease therapeutics Sabue. N Engl J Med. 2019;381:2293-303.

18. Brown AJ, Won JJ, Graham RL, Dinnon KH, Sims AC, Feng JY, et al. Broad spectrum antiviral remdesivir inhibits human endemic and zoonotic deltacoronaviruses with a highly divergent RNA dependent RNA polymerase. Antivir Res. 2019;169:1-10.

19. Wang M, Cao R, Zhang L, Yang X, Liu J, Xu M, et al. Remdesivir and chloroquine effectively inhibit the recently emerged novel coronavirus ( 2019-nCoV ) in vitro. Cell Res. 2020;30:269-71.

20. Williamson BN, Feldmann F, Schwarz B, Meadewhite K, Porter DP, Schulz J et al. Clinical benefit of remdesivir in rhesus macaques infected with SARS-CoV-2 Brandi. bioRxiv. 2020;https://doi.org/ 10.1101/2020.04.15.043166.

21. Holshue ML, DeBolt C, Lindquist S, Lofy KH, Wiesman J, Bruce $\mathrm{H}$, et al. First case of 2019 novel coronavirus in the United States. N Engl J Med. 2020;382:929-36. 
22. Grein J, Ohmagari N, Shin D, Diaz G, Asperges E, Castagna A, et al. Compassionate use of remdesivir for patients with severe Covid-19. N Engl J Med. 2020. https://doi.org/10.1056/ NEJMoa2007016.

23. Wang Y, Zhang D, Du PG, Du PR, Zhao PJ, Jin PY, et al. Remdesivir in adults with severe COVID-19: a randomised, double-blind, placebo-controlled, multicentre trial. Lancet. 2020. https://doi.org/10.1016/S0140-6736(20)31022-9.

24. Beigel JH, Tomashek KM, Dodd LE, Mehta AK, Zingman BS, Kalil AC, et al. Remdesivir for the treatment of Covid-19 - preliminary report. N Engl J Med. 2020:1-12.

25. Goldman JD, Lye DCB, Hui DS, Marks KM, Bruno R, Montejano $\mathrm{R}$, et al. Remdesivir for 5 or 10 days in patients with severe Covid19. N Engl J Med. 2020:1-11.

26. Delang L. Favipiravir as a potential countermeasure against neglected and emerging RNA viruses. 2020;3-5.

27. Furuta Y. Favipiravir (T-705), a broad spectrum inhibitor of viral RNA polymerase. Proc Jpn Acad. 2017;93:449-63.

28. Cai Q, Yang M, Liu D, Chen J, Shu D, Xia J, et al. Experimental treatment with favipiravir for COVID-19: an open-label control study. Engineering. 2020. https://doi.org/10.1016/j.eng.2020.03. 007.

29. Chen C, Huang J, Cheng Z, Wu J, Chen S, Zhang Y, et al. Favipiravir versus Arbidol for COVID-19: a randomized clinical trial. medRxiv. 2020;https://doi.org/10.1101/2020.03.17. 20037432.

30. Madelain V, Huyen T, Nguyen T, Mentré F. Ebola virus infection: a review on the pharmacokinetic and pharmacodynamic properties of drugs considered for testing in human efficacy trials. Clin Pharmacokinet. 2016;55:907-23.

31. Madelain V, Guedj J, Mentre F, Huyen T, Jacquot FOL, et al. Favipiravir pharmacokinetics in nonhuman primates and insights for future efficacy studies of hemorrhagic fever viruses. Antimicrob Agents Chemother. 2017;61:1-12.

32. Chu CM, Cheng VCC, Hung IFN, Wong MML, Chan KH, chuChan $\mathrm{K}$, et al. Role of lopinavir/ritonavir in the treatment of SARS: initial virological and clinical findings. Respir Infect. 2004;59:252-6.

33. De Wilde AH, Jochmans D, Posthuma CC, Zevenhoven-dobbe JC, Van Nieuwkoop S. Screening of an FDA-approved compound library identifies four small-molecule inhibitors of Middle East respiratory syndrome coronavirus replication in cell culture. Antimicrob Agents Chemother. 2014;58:4875-84.

34. Cao B, Wang Y, Wen D, Liu W, Wang J, Fan G, et al. A trial of lopinavir-ritonavir in adults hospitalized with severe Covid-19. N Engl J Med. 2020;382:1787-99.

35. Hung IF, Lung K, Tso EY, Liu R, Chung TW, Chu M, et al. Triple combination of interferon beta- $1 \mathrm{~b}$, lopinavir-ritonavir , and ribavirin in the treatment of patients admitted to hospital with COVID-19 : an open-label, randomised, phase 2 trial. Lancet. 2020:1-10.

36. Savarino A, Di Trani L, Donatelli I, Cauda R, Cassone A. New insights into the antiviral effects of chloroquine. Lancet Infect Dis. 2006;6:67-9.

37. Yan Y, Zou Z, Sun Y, Li X, Xu KF, Wei Y, et al. Anti-malaria drug chloroquine is highly effective in treating avian influenza A H5N1 virus infection in an animal model. Cell Res. 2013;23:300-2.

38. Vincent MJ, Bergeron E, Benjannet S, Erickson BR, Rollin PE, Ksiazek TG, et al. Chloroquine is a potent inhibitor of SARS coronavirus infection and spread. Virol J. 2005;2:1-10.

39. Gao J, Tian Z, Yang X. Breakthrough: Chloroquine phosphate has shown apparent efficacy in treatment of COVID-19 associated pneumonia in clinical studies. Biosci Trends. 2020;14:72-3.

40. Gautret P, Lagier JC, Parola P, Hoang VT, Meddeb L, Mailhe M, et al. Hydroxychloroquine and azithromycin as a treatment of COVID-19: results of an open- label non-randomized clinical trial.
Int J Antimicrob Agents. 2020. https://doi.org/10.1016/j. ijantimicag.2020.105949.

41. Jun CHEN, Danping LIU, Li LIU, Ping LIU, Qingnian XULX, et al. A pilot study of hydroxychloroquine in treatment of patients with moderate COVID-19. Zhejiang Da Xue Xue Bao Yi Xue Ban. 2019;49:215-9.

42. Tang W, Cao Z, Han M, Wang Z, Chen J SW et al. Hydroxychloroquine in patients mainly with mild to moderate COVID-19: an open-label, randomized, controlled trial. medRxiv. 2020;https://doi.org/10.1101/2020.04.10.20060558.

43. Borba MGS, Val F de A, Sampaio VS, Alexandre MAA, Melo GC, Brito $\mathrm{M}$, et al. Chloroquine diphosphate in two different dosages as adjunctive therapy of hospitalized patients with severe respiratory syndrome in the context of coronavirus (SARS-CoV-2) infection: Preliminary safety results of a randomized, double-blinded, phase IIb cl. medRxiv. 2020;https://doi.org/10.1101/2020.04.07. 20056424.

44. Mehra MR, Desai SS, Ruschitzka F, Patel AN. Articles Hydroxychloroquine or chloroquine with or without a macrolide for treatment of COVID-19: a multinational registry analysis. Lancet. 2020:1-10. Available from:. https://doi.org/10.1016/ S0140-6736(20)31180-6.

45. Shanmugaraj B, Siriwattananon K, Wangkanont KPW. Perspectives on monoclonal antibody therapy as potential therapeutic intervention for coronavirus disease-19 (COVID-19). Asian Pac J Allergy Immunol. 2020;38:10-8.

46. Pang J, Wang MX, Ang IYH, Tan SHX, Lewis RF, Chen JI-P, et al. Potential rapid diagnostics, vaccine and therapeutics for 2019 novel coronavirus (2019-nCoV): a systematic review. J Clin Med. 2020;9:1-33.

47. Zhou B, Zhong N, Guan Y. Treatment with convalescent plasma for influenza A (H5N1) infection. N Engl J Med. 2007;357:1450-1.

48. Van Griensven J, Edwards T, De Lamballerie X, Semple MG, Gallian P, Baize S, et al. Evaluation of convalescent plasma for Ebola virus disease in Guinea. N Engl J Med. 2016;374:33-42.

49. Rinaldo CR. Passive immunization against poliomyelitis: the Hammon gamma globulin field trials, 1951-1953. Am J Public Health. 2005;95:790-9.

50. Shen C, Wang Z, Zhao F, Yang Y, Li J, Yuan J, et al. Treatment of 5 critically ill patients with COVID-19 with convalescent plasma. JAMA. 2020;323:1582-9.

51. Zhang Q, Wang Y, Qi C, Shen L, Li J. Clinical trial analysis of 2019-nCoV therapy registered in China. J Med Virol. 2020;92: 540-545.

52. Wong SK, Li W, Moore MJ, Choe H, Farzan M. A 193-amino acid fragment of the SARS coronavirus S protein efficiently binds angiotensin-converting enzyme 2. J Biol Chem. 2004;279:3197201.

53. Channappanavar R, Perlman S. Pathogenic human coronavirus infections: causes and consequences of cytokine storm and immunopathology. Semin Immunopathol. 2017;39:529-39.

54. Chousterman BG, Swirski FKWG. Cytokine storm and sepsis disease pathogenesis. Semin Immunopathol. 2017;39:517-28.

55. Ruan Q, Yang K, Wang W, Jiang L, Song J. Clinical predictors of mortality due to COVID-19 based on an analysis of data of 150 patients from Wuhan, China. Intensive Care Med. 2020; Available from:. https://doi.org/10.1007/s00134-020-05991-x.

56. Ramanathan K, Antognini D, Combes A, Paden M, Zakhary B, Ogino M, et al. Epidemiological and clinical characteristics of 99 cases of 2019 novel coronavirus pneumonia in Wuhan, China: a descriptive study. Lancet. 2020;395:507-13.

57. Wu C, Chen X, Cai Y, Xia J, Zhou X, Xu S, et al. Risk factors associated with acute respiratory distress syndrome and death in patients with coronavirus disease 2019 pneumonia in Wuhan, China. JAMA Intern Med. 2020:1-24. 
58. Liu T, Zhang J, Yang Y, Zhang L, Ma H, Li Z, et al. The potential role of IL-6 in monitoring coronavirus disease 2019. medRxiv. 2020;https://doi.org/10.1101/2020.03.01.20029769.

59. Xu X, Han M, Li T, Sun W, Wang D, Fu B, et al. Effective treatment of severe COVID-19 patients with tocilizumab. chinaXiv. 2020;.

60. Hammer Q, Rückert T, Romagnani C. Natural killer cell specificity for viral infections. Nat Immunol. 2018;19:800-8.

61. Dai HS, Caligiuri MA. Molecular basis for the recognition of Herpes simplex virus type 1 infection by human natural killer cells. Front Immunol. 2018;9:1-8.

62. Arase H, Mocarski ES, Campbell AE, Hill AB, Lanier LL. Direct recognition of cytomegalovirus by activating and inhibitory NK cell receptors. Science. 2002;296:1323-6.

63. Xu LL, Wang Z, Zhi-Qiang Q, Tong Z-H, Wang C, Xia CQ. The involvement of natural killer cells in the pathogenesis of severe acute respiratory syndrome. Am J Clin Pathol. 2004;121:507-11.

64. Moodley Y, Atienza D, Manuelpillai U, Samuel CS, Tchongue J, Ilancheran S, et al. Human umbilical cord mesenchymal stem cells reduce fibrosis of bleomycin-induced lung injury. Am J Pathol. 2009;175:303-13.

65. Ortiz LA, DuTreil M, Fattman C, Pandey AC, Torres G, Go K, et al. Interleukin 1 receptor antagonist mediates the antiinflammatory and antifibrotic effect of mesenchymal stem cells during lung injury. Proc Natl Acad Sci U S A. 2007;104:11002-7.

66. Gupta N, Su X, Popov B, Lee JW, Serikov V, Matthay MA. Intrapulmonary delivery of bone marrow-derived mesenchymal stem cells improves survival and attenuates endotoxin-induced acute lung injury in mice. J Immunol. 2007;179:1855-63.

67. Zumla A, Wang F, Ippolito G, Petrosillo N, Agrati C, Azhar E, et al. Reducing mortality and morbidity in patients with severe COVID19 disease by advancing ongoing trials of Mesenchymal Stromal (stem) Cell (MSC) therapy - Achieving global consensus and visibility for cellular host-directed therapies. Int J Infect Dis. 2020;96:431-439.

68. Leung PC. The efficacy of Chinese medicine for SARS: a review of Chinese publications after the crisis. Am J Chin Med. 2007;35:57581.
69. Yang Y, Islam MS, Wang J, Li Y, Chen X. Traditional Chinese medicine in the treatment of patients infected with 2019-new coronavirus (SARS-CoV-2): a review and perspective. Int J Biol Sci. 2020;16:1708-17.

70. Chen H, Du Q. Potential natural compounds for preventing SARSCoV-2 (2019-nCoV) infection. Preprints. 2020; https://doi.org/10. 20944/preprints202001.0358.v3.

71. Luo H, Tang Q 1, Shang Y x, Liang S b, Yang M, Robinson N, et al. Can Chinese medicine be used for prevention of corona virus disease 2019 (COVID-19)? A review of historical classics, Research Evidence and Current Prevention Programs. Chin J Integr Med. 2020;26:243-50.

72. Gyawali R, Paudel PN, Basyal D, Setzer WN, Lamichhane S, Kumar M, et al. Review Article A review on ayurvedic medicinal herbs as remedial perspective for article info. 2020;3.

73. Islam MT, Sarkar C, El-Kersh DM, Jamaddar S, Uddin SJ, Shilpi JA, et al. Natural products and their derivatives against coronavirus: a review of the non-clinical and pre-clinical data. Phytother Res. 2020. https://doi.org/10.1002/ptr.6700.

74. Mani JS, Johnson JB, Steel JC, Broszczak DA, Neilsen PM, Walsh $\mathrm{KB}$, et al. Natural product-derived phytochemicals as potential agents against coronaviruses: a review. Virus Res. 2020;284.

75. Rajkumar RP. Ayurveda and COVID-19: where psychoneuroimmunology and the meaning response meet. Brain Behav Immun. Elsevier; 2020;87:8-9. Available from: https://doi.org/10.1016/j. bbi.2020.04.056

76. Balasubramani SP, Venkatasubramanian P, Kukkupuni SK, Patwardhan B. Plant-based Rasayana drugs from Ayurveda. Chin J Integr Med. 2011;17:88-94.

77. Tillu G, Chaturvedi S, Chopra A, Patwardhan B. Public health approach of ayurveda and yoga for COVID-19 prophylaxis. J Altern Complement Med. 2020;26:360-4.

Publisher's Note Springer Nature remains neutral with regard to jurisdictional claims in published maps and institutional affiliations. 